\title{
Optimization of nutrient concentration for citric acid production by solid-state culture of Aspergillus niger on polyurethane foams
}

\author{
J. Pintado, A. Torrado, M. P. Gonzalez, and M. A. Murado \\ Instituto de Investigacions Mariñas (CSIC), Vigo, Galicia, Spain \\ Address reprint requests to Dr. J. Pintado, Instituto de Investigacions Mariñas (CSIC) \\ rua Eduardo Cabello, 6, Vigo 36208, Galicia, Spain.
}

Citric acid production from mussel processing effluents by Aspergillus niger in solidstate culture was studied using polyurethane foam particles soaked with the culture medium. Conditions were used that allowed comparison of the results with those obtained before in submerged culture and the attribution of the differences to the characteristics of solid-state culture.

A screening of several strains gave different results than in submerged culture and a reduction in the incubation time. The joint effect of nitrogen and phosphorus initial concentrations was examined by means of orthogonal factorial designs in five selected strains. The results showed that different requirements of $\mathrm{N}$ and $\mathrm{P}$ for each individual strain were needed. Optimization was done using different experimental strategies for two selected strains. Following either the direction of the linear approximation gradient of the first-order empirical model obtained or with a new rotatable factorial design, an optimum value could be obtained.

In comparison with previous results in submerged culture, the strains with high requirements of $\mathrm{N}$ and $\mathrm{P}$ seemed to be disfavored in solid-state culture. The ones with low requirements were favored and showed a bigger tolerance to a surplus of both nutrients.

Keywords: Solid-state culture; citric acid production; mussel processing wastes; nutrient optimization; empirical models; Aspergillus niger

Introduction 
Citric acid production is one of the possible procedures for exploitation of mussel processing wastes (MPW). This effluent, generated in the steam treatment of mussel, constitute (due to their high volume and organic load, average COD: $25 \mathrm{~g} \mathrm{O}_{2} \mathrm{l}^{-1}$; glycogen as main component: $10 \mathrm{~g} \mathrm{l}^{-1}$ ) an important eutrofication factor in the Galician Rias Baixas estuaries (Northwest coast of Spain). The process developed by our group initially in submerged culture (SC) ${ }^{1-4}$ demonstrated the suitability of this media for citric acid production, the redundancy of pretreatment, and the importance of nitrogen and phosphorus concentrations. ${ }^{5,6}$ At present, our work has been redirected toward the development of solidstate culture (SSC) processes. This type of culture has shown positive results for citric acid production in previous reports ${ }^{7}$ and has advantages over $\mathrm{SC}$. One of these is that SSC requires less economic investment, an important aspect when the intention is to encourage the application of methods for the treatment of wastes. Furthermore, the development in SSC of other bioproductions based on MPW also showed a production comparable or superior to that in $\mathrm{SC}^{8,9}$

Traditionally, SSC are characterized by the development of microorganisms in a lowwater activity environment on a nonsoluble material that acts both as physical support and source of nutrients; ${ }^{10}$ however, it is not necessary to combine the role of support and substrate, but rather reproduce the conditions of low-water activity and high oxygen transference by using a nutritionally inert material soaked with a nutrient solution. ${ }^{7-}$ 9,11,12 Apart from the fact that this is the only possible option for utilization of a liquid waste like MPW, this SSC system shows interesting advantages from both theoretical and practical points of view. It permits the composition of the culture medium and support-depending (such as particle diameter or porosity) or interface-depending (as proportion of liquid phase in the system) physical factors to be varied independently. At the same time and most important for this work, this system allows a direct comparison with $\mathrm{SC}$, and so to attribute the different results, using the same strains and culture medium composition, to the features of each type of culture.

Strain selection is an important factor for achieving high yield of citric acid. For each strain, the requirements of nitrogen and phosphorus concentration in the initial medium shows a great variability. ${ }^{5}$ The performance of the different strains depends also on the type of culture used. In fact, strains suitable for production in SC may not be suitable for solid-state production; ${ }^{13}$ moreover, the properties of SSC can condition the effect of 
nutrients such as metal ions and minerals and consequently determine different optimal levels. $^{14}$

Nitrogen and phosphorus limitation are crucial factors in citric acid production by Aspergillus niger. ${ }^{15-17}$ The negative effect of their excess makes hyperbolic models such as Michaelis and Menten or Monod type inadequate and unsuitable for optimizing nutrient concentration for citric acid production improvement. On the other hand, the interaction between both nutrients makes the study of their combined effect necessary as observed in our previous work ${ }^{5}$ and by other authors. ${ }^{18}$ To overcome both problems, empirical models based on factorial orthogonal or rotatable designs have proven to be useful. $^{5}$ In previous work ${ }^{19}$ in fed-batch SC, nitrogen showed a regulating role important in production and having two effects. One effect was negative since, in excess, $\mathrm{N}$ promoted a bigger growth and consequently diverted the source of carbon toward energy and biomass production. The other effect was positive because a moderate input contributed to the maintenance of citric acid productive biomass.

The objective of this work has been to check the capability of different strains of A. niger in SSC and to establish the requirements of nitrogen and phosphorus in the culture medium. This was done applying the same methodology used for an analogous study employing SC. ${ }^{5}$ It was possible, therefore, to compare the tendencies resulting from the respective empirical models obtained for the same strains directly. Differences in behavior were shown to be conditioned by the type of culture.

Materials and methods

Microorganism and inoculum preparation

The 11 A. niger strains used (CBS, Baarn, Holland, identification numbers in Figure 1) were maintained on malt-yeast extract agar slants at $4^{\circ} \mathrm{C}$ by subculturing every month. For inoculum preparation, the spores were grown on a slant at $30^{\circ} \mathrm{C}$ for 7 days, and were scraped in distilled water solution. The spore density was measured by optical density measurement at $750 \mathrm{~nm}$ following calibration between this data and direct hemocytometer counting. The suspensions were centrifuged and the spores resuspended in the appropriate volume of culture medium. 
Fermentation medium and culture conditions

The processing of MPW (clarification, concentration, and hydrolysis) were as described elsewhere. ${ }^{4}$ The basic medium $(10 \mathrm{M}-\mathrm{H})$ used contained in $\mathrm{g}^{-1}$ : glucose, 108 ; total nitrogen, 0.710; and total phosphorus, 0.060 . The main fraction ( 95\%) of the nitrogen content was of proteic nature and approximately $75 \%$ could be used by A. niger. ${ }^{19}$ Initial $\mathrm{pH}$ of the medium was adjusted to 4.0 with $5 \mathrm{~N} \mathrm{HCl}$.

Solid-state culture was always prepared under conditions established in previously published results. ${ }^{7}$ The support was a commercial polyurethane foam with density $60 \mathrm{~g}$ $\mathrm{dm}^{-3}$ (COPO Iberica) cut into cylindrical particles with a diameter and height of $6 \mathrm{~mm}$. The load per experimental unit (50 ml Erlenmeyer flask) was $0.372 \mathrm{~g}$, approximately 40 foam cylinders, equivalent to an apparent volume of support of $6.2 \mathrm{~cm}^{3}$. The addition of liquid culture medium was done so that the foam attained $50 \%$ of the total liquid retention capacity which implies a volume of $2.83 \mathrm{ml}$ per experimental unit.

Sterilization was performed by steaming for $1 \mathrm{~h}$. Each experimental unit was inoculated with $20 \times 10^{6}$ suspended spores in a suitable volume of each culture medium under sterile conditions. The incubations were performed at $30^{\circ} \mathrm{C}$ in a heater with constant humidity and static conditions. To avoid possible agglomerations of the material due to fungal growth, the cultures were manually shaken once a day.

Factorial design

Empirical models for the production of citric acid with respect to nitrogen and phosphorus concentration were calculated for the different strains of A. niger. These models were obtained by means of a complete first-order orthogonal plan with quadruple replication in the center of the domain according to the procedures described by Akhnazarova and Kafarov ${ }^{20}$ and Box et al. ${ }^{21}$ The strategies of optimization used with the most interesting strains were an extension of the experimental domain guided by the linear approximation gradient method (LAG) and the use of a second-order rotatable plan. 
Extraction of the samples

At preestablished times, the whole content of each experimental unit was analyzed. The foam support was compressed in a syringe and washed repeatedly with distilled water. The extracts thus obtained were centrifuged at 5,000 rpm, and the analytical determinations performed on the corresponding supernatants. The sediment was added to the rest of the washed material for biomass estimation.

Analytical methods

Reducing sugars were estimated by means of the 3,5-dinitrosalicylic acid reaction ${ }^{22}$ with glucose as standard. Citric acid was measured by the spectrophotometric method of Marrier and Boulet. ${ }^{23}$ Biomass was estimated by drying the washed material of each experimental unit over $\mathrm{P}_{2} \mathrm{O}_{5}$ under reduced pressure in a dessicator/oven at $55^{\circ} \mathrm{C}$ and then weighing. All analyses were performed in duplicate.

Results

Screening of the aptitude of different strains of A. niger for citric acid production

To select the better producing strains in SSC, a screening of the 11 available strains was conducted with the culturing conditions described above and using the concentration of nutrients in the liquid phase: glucose, $108 \mathrm{~g} \mathrm{l}^{-1}$; total nitrogen, $955 \mathrm{mg} \mathrm{l}^{-1}$, and total phosphorus, $90 \mathrm{mg} \mathrm{l}^{-1}$. The results were compared with those obtained in SC with the same medium under the conditions described elsewhere. ${ }^{5}$

The results obtained in SSC (Figure 1) showed an almost exhaustive consumption of the carbon source in most of the strains after an incubation period of $96 \mathrm{~h}$. This is much earlier than in SC, which takes about $192 \mathrm{~h}$. Later cultures confirmed that the maximum production of acid in SSC takes place between 48-72 h. Bearing this in mind, it can be supposed that in some cases, the determination of the produced acid was conducted already in a postoptimal phase. Despite this, the productivity of the individual strains in SSC showed marked differences with that obtained in SC. 
Strains CBS 554-65, 120-49, 126-48, 246-65, and 733-88 were selected with the first two showing particularly good yields. (554-65 showed very similar productions in both modalities of culture). As with $\mathrm{SC}^{5}$ the optimum concentration of nutrients (mainly nitrogen and phosphorus) may depend on the strain; therefore, the production of the five selected strains was studied with a wider range of concentrations of both nutrients.

Joint effect of initial levels of $\mathrm{N}$ and $\mathrm{P}$ in the selected strains

As described previously, surplus $\mathrm{N}$ or $\mathrm{P}$ exert a depressive effect on citric acid production in SC. Even at low levels, the optimum requirements of both nutrients depended greatly in the strain considered; ${ }^{5}$ thus, for studying an analogous behavior in SSC and with the aim of comparing the results, this aspect was studied with the selected strains by means of a first-order orthogonal factorial plan in the same experimental domain assayed in SC (Table 1).

With the culture conditions described, sampling time was reduced to $72 \mathrm{~h}$ (increasing production of the acid before carbohydrate exhaustion). The criterion for model acceptance was based on the Student's t test $(\alpha<0.05)$ for the coefficients and on the Fisher's F test (also $\alpha<0.05$ ) applied to the ratios: experimental error/total error and lack of fit/experimental error for the global validity.

At such levels of significance, only the behavior of strain 120-49 could be described by means of a linear model (Table 2). For the others, the model was acceptable with respect to the relation total error/experimental error, but it was not in regard to the relation lack of fit/experimental error, showing the existence of more or less pronounced curvatures; nevertheless, the results obtained (Figure 2) allowed selection criteria and the improvement direction to be established as discussed below.

Strain 554-65 clearly performed as the most efficient for citric acid production in this culturing mode as it did in SC. The linear model is not appropriate, suggesting a secondorder effect in one or both of the variables. The response increases with increasing levels of both variables with a maximum value at $\mathrm{N}=+1, \mathrm{P}=+1$, and extrapolation shows that the optimum lies at higher values of $\mathrm{N}$ and $\mathrm{P}$ out of the experimental domain assayed. 
With the strain CBS 120-49, although the standardized residuals show a shallow curvature (Figure 3), it can be approximated by a linear model:

$\operatorname{CIT}\left(\mathrm{g} \mathrm{l}^{-1}\right)=9.45+1.55 \mathrm{~N}+2.20 \mathrm{P}+1.67 \mathrm{NP}$

which also predicts improvement of the response toward high levels of both nutrients.

Similarly with strain $126-48$, best results were obtained in the medium with high values of $\mathrm{N}$ and $\mathrm{P}$. Here, lowering one or both $\mathrm{N}$ and $\mathrm{P}$ levels promotes a bigger decrease in the production than CBS 120-49.

Strain 246-65 improves toward high values of $\mathrm{N}$ and low values of $\mathrm{P}$. The difficulty in reducing $\mathrm{P}$ levels of MPW make the increase in the concentration of $\mathrm{N}$ the most feasible way to adjust relative concentrations. As a result, this strain is less interesting.

With the strain 733-88, maximum production obtained in the center of the domain suggests that the location of the optimum would only require the experimental enlargement of the domain with four the points needed for a rotatable design; nevertheless, it does not seem foreseeable that the optimum surpasses substantially the results already obtained, and never the ones obtained with strains 554-65 and 120-49.

Extrapolation of the model obtained for strain CBS 120-49

Although the results of this strain are less interesting from the point of view of the total production reached, the empirical model obtained suggests the possibility of improving production simply by increasing initial levels of $\mathrm{N}$ and $\mathrm{P}$. Considering experimental economy, the enlargement of the experimental domain was done applying the linear gradient approximation (LAG) method to Eq. (1) beginning from the center (in coded values, $\mathrm{N}=0 ; \mathrm{P}=0$ ), determining each new point by:

$\mathrm{N}_{\mathrm{n}}=\mathrm{N}_{(\mathrm{n}-1)}+(\partial \mathrm{CIT} / \partial \mathrm{N}) \Delta \mathrm{N}$ and

$\mathrm{P}_{\mathrm{n}}=\mathrm{P}_{(\mathrm{n}-1)}+(\partial \mathrm{CIT} / \partial \mathrm{P}) \Delta \mathrm{P}$

assigning equal increments in $\Delta \mathrm{N}$ and $\Delta \mathrm{P}$ of $1 / 40$ of the domain ( 0.05 in coded values). Although this method gives good predictions within the domain, an area in which $\mathrm{N}$ and $P$ have not yet had a deleterious effect, it is foreseeable that by increasing gradually both nutrients, a maximum of citric acid will be reached and after it, production will drop. 
The five points of the LAG assayed appear (defined by coded and natural values) in Table 3. Cultures were conducted in a $10 \mathrm{M}-\mathrm{H}$ medium with the required supplements and under the same conditions and incubation times as in the previous culture.

In contrast to the theoretical extrapolation, the experimental results showed the limitation of improving the production in this way (Figure 4). After a slight increase (smaller than predicted) up to the point $\mathrm{N}=1,211 ; \mathrm{P}=142 \mathrm{mg} \mathrm{l}^{-1}$, the production of the acid drops with an almost parabolic trajectory. $\mathrm{N}$ and $\mathrm{P}$ concentrations above $\mathrm{N}=1,552$ and $\mathrm{P}=195 \mathrm{mg} \mathrm{l}^{-1}$ inhibit citric acid production completely. The increment in biomass production follows an asymptotic type curve and carbohydrate consumption declines from a maximum situated further on than the one for the production of citric acid.

The LAG method was thus useful for establishing the optimal range of interacting variables using a small number of experiments. Based on this, a rotatable second-order plan could be conducted to establish the precise optimal values, but in this case, no important further improvement can be expected which would justify the selection of this strain.

A rotatable design for strain CBS 554-65

In view of the inadequacy of a first-order model for describing the production response, this suggests second-order effects in at least one of the variables. The original domain was enlarged toward higher values of $\mathrm{N}$ and $\mathrm{P}$ with the necessary points needed for a second-order rotatable plan (Table 4) centered on the limit of higher production $(\mathrm{N}+1$, $P+1)$. The unitary increments for the natural values were the same as in the previous plan.

The results after $60 \mathrm{~h}$ of incubation allowed description of the effects of $\mathrm{N}$ and $\mathrm{P}$ on three parameters (citric acid, biomass production, and consumed glucose) by means of empirical second-order equations whose validity was tested with the same criteria as before (Table 5 and Figure 5). The response surfaces are shown in Figure 6.

1. Citric acid: Eq. (2) obtained for this response reflects the significant interaction between $\mathrm{N}$ and $\mathrm{P}$ as well as a large negative quadratic effect in both variables: 
$\operatorname{CIT}\left(\mathrm{g} \mathrm{l}^{-1}\right)=39.62+3.99 \mathrm{~N}+0.92 \mathrm{P}+1.90 \mathrm{NP}-4.26 \mathrm{~N}^{2}-2.96 \mathrm{P}^{2}$

The calculated optimum corresponds to the point $\mathrm{N}=0.69 ; \mathrm{P}=0.48$ (equivalent to $\mathrm{N}=$ 1,416 and $\mathrm{P}=140 \mathrm{mg} \mathrm{l}^{-1}$ ) with a predicted production of $40.73 \mathrm{~g} \mathrm{l}^{-1}$ verified experimentally by obtaining a production of $40.01 \mathrm{~g} \mathrm{l}^{-1}$.

2. Biomass: Eq. (3) shows a clear effect due to $\mathrm{N}$ with $\mathrm{P}$ appearing only in the interaction term.

$\mathrm{B}\left(\mathrm{g} \mathrm{l}^{-1}\right)=20.27+2.09 \mathrm{~N}+0.87 \mathrm{NP}-1.10 \mathrm{~N}^{2}$

In fact, raising the constraints of the Student's test to the level a , 0.01, Eq. (4) is reduced to:

$\mathrm{B}\left(\mathrm{g} \mathrm{l}^{-1}\right)=20.27+2.09 \mathrm{~N}-1.01 \mathrm{~N}^{2}$

so that $\mathrm{P}$ disappears and yet passes both Fisher's tests at a level $\alpha<0.05$.

With regard to Eq. (3) and (Figure 6), high levels of biomass require a high initial concentration of both nutrients, although the variable P shows a linear effect of different sign depending on the level of $\mathrm{N}$-an interaction that demonstrates the need for balance between the nutrients.

3. Consumed glucose: Although this response is largely affected by N, it only takes place with low values of $\mathrm{P}$ :

$\mathrm{Gc}\left(\mathrm{g} \mathrm{l}^{-1}\right)=80.45+10.43 \mathrm{~N}-3.37 \mathrm{P}-1.84 \mathrm{NP}-4.32 \mathrm{~N}^{2}$

The effect of $\mathrm{N}$ can be related directly with biomass production, but it is more difficult to explain the negative effect of $P$.

Comparing the surfaces obtained for the different responses, it should be noted that the production of the acid does not depend directly on the total biomass production and that with glucose consumption up to medium levels of nutrients, it is not always correlated with production of biomass and/or citric acid.

\section{Discussion}

It has been shown that SSC develops at a higher rate, reaching maximum production in about 2-3 days; SC takes 8-10 days. The productivity of the different strains and their nutritional requirements also vary with the culturing mode. This work shows the utility 
of factorial designs for establishing these requirements by allowing not only the selection of the most interesting strains but also the criteria for improved performance. It is evident that this type of procedure is well suited to locating the optimum production, particularly in the case of variables with important interactions as demonstrated in this work.

Comparing the results in SSC with the corresponding results in SC for same strains ${ }^{5}$ (Table 6) and referring to the tendencies of production as a function of the levels of $\mathrm{N}$ and $\mathrm{P}$, it can be appreciated how the culturing modality conditions the behavior of the microorganism. For both culturing methods, the strains 554-65, 120-49, and 126-48 showed a similar behavior, but with improvement toward low levels of $\mathrm{N}$ and $\mathrm{P}$ in SC and toward high levels in SSC, and with superior productions and yields in the latter. In contrast, for strains 264-65 and 733-88, higher levels of $\mathrm{N}$ and $\mathrm{P}$ improved production in SC and decreased it in SSC.

This could be interpreted in accordance with Ramesh and Lonsane ${ }^{24}$ and Shankaranand and Lonsane ${ }^{14}$ who recognized that the specificity of SSC is largely due to a lower diffusion rate of nutrients and metabolites that occurs in low-water activity conditions; thus, the strains with high requirements of $\mathrm{N}$ and $\mathrm{P}$ seem to be disfavored as a consequence of the restrictions of accessibility to the nutrients in the medium. These restrictions would also explain the bigger tolerance to a surplus of $\mathrm{N}$ and $\mathrm{P}$ detected in the strains in which the response decreases.

For strain 554-65, citric acid production in SSC can be compared with the equation obtained previously for the same domain and with the same unitary increments of $\mathrm{N}$ and $\mathrm{P}$ in SC, although of first order (6):

$\operatorname{CIT}\left(\mathrm{g}^{-1}\right)=22.4-9.3 \mathrm{~N}-4.3 \mathrm{P}$

It can be noted that, besides a change in the requirements, both nutrients have a lower effect in SSC with smaller values of the $\mathrm{N}$ and $\mathrm{P}$ coefficients compared with the independent term, so this system is less sensitive within the same range of variables.

This work demonstrates differences in behavior between the two culturing modes, although more work should be done to elucidate whether these differences are due to diffusional restrictions or other factors such as morphological and physiological 
changes induced by the growth of the fungus on a support. From a more practical point of view, the results of this work indicate the advantages of SSC for bioproduction when based on residual substrates such as MPW, particularly in reducing the effect of varying composition.

Acknowledgments

The authors thank Nachi Montemayor for technical help and Dr. James Connelly for comments and manuscript revision. J. Pintado thanks Caixavigo (Spain) for the research fellowship.

\section{References}

1. Gonzalez, M. P., Siso, M. I. G., Murado, M. A., Pastrana, L., Montemayor, M. I., and Miron, J. Depuration and valuation of mussel-processing wastes. Characterization of amylolytic postincubates from different species grown on an effluent. Biores. Technol. 1992, 42, 133-140

2. Murado, M. A., Siso, M. I. G., Gonzalez, M. P., Montemayor, M. I., Pastrana, L., and Pintado, J. Characterization of microbial biomasses and amylolytic preparations obtained from mussel processing waste treatment. Biores. Technol. 1993, 43, 117125

3. Murado, M. A., Gonzalez, M. P., and Pastrana, L. Mussel processing wastes as a fermentation substrate. In: Fisheries Processing: Biotechnological Applications (Martin, A. M., Ed.). Chapman and Hall, London, 1994, 311-343

4. Murado, M. A., Gonzalez, M. P., Pastrana, L., Siso, M. I. G., Miron, J., and Montemayor, M. I. Enhancement of the bioproduction potential of an amylaceous effluent. Biores. Technol. 1993, 44, 155-163

5. Pintado, J., Murado, M. A., Gonzalez, M. P., Miron, J., and Pastrana, L. Joint effect of nitrogen and phosphorus concentrations on citric acid production by different strains of Aspergillus niger grown on an effluent. Biotechnol. Lett. 1993, 15, $1157-$ 1162

6. Pintado, J., Gonzalez, M. P., and Murado, M. A. Interactions between pretreatment and nutrient concentrations of mussel processing effluents for citric acid production. Enzyme Microb. Technol. 1997, 20, 544-549 
7. Pintado, J., Torrado, A., Miron, J., Montemayor, M. I., Gonzalez, M. P., Murado, M. A., and Sanroman, A. Citric acid production from mussel processing wastes in solid state culture. Med. Fac. Landbouww. Univ. Gent. 1994, 59, 2429-2437

8. Pastrana, L., Gonzalez, M. P., Pintado, J., and Murado, M. A. Interactions affecting gibberellic acid production in solid-state culture. A factorial study. Enzyme Microb. Technol. 1995, 17, 784-790

9. Murado, M. A., Gonzalez, M. P., Torrado, A., and Pastrana, L. M. Amylase production by solid state culture of Aspergillus oryzae on polyurethane foams. Some mechanistic approaches from an empirical model. Proc. Biochem. 1997, 32 , $35-42$

10. Mitchell, D. A. and Lonsane, B. K. Definition, characteristics, and potential. In: Solid Substrate Cultivation (Doelle, H. W., Mitchell, D. A., and Rolz, C. E., Eds.). Elsevier Science Publishers Ltd., Barking, England, 1992, 1-16

11. Viniegra-Gonzalez, G. Solid state fermentation: Definition, characteristics, limitations and monitoring. In: Advances in Solid Substrate Fermentation (Roussos, S., Lonsane, B. K., Raimbault, M., and Viniegra-Gonzalez, G., Eds.). Kluwer Academic Publishers, Dordrecht, The Netherlands, 1997, 5-22

12. Gutierrez-Rojas, M., Cordova, J., Auria, R., Revah, S., and Favela- Torres, E. Citric acid and polyols production by Aspergillus niger at high glucose concentration in solid state fermentation on inert support. Biotechnol. Lett. 1995, 17, 219-224

13. Shankaranand, V. S., Ramesh, M. V., and Lonsane, B. K. Idiosyncrasies of solidstate fermentation systems in the biosynthesis of metabolites by some bacterial and fungal cultures. Proc. Biochem. 1992, 27, 33-36

14. Shankaranand, V. S. and Lonsane, B. K. Ability of Aspergillus niger to tolerate metal ions and minerals in solid-state fermentation system for the production of citric acid. Proc. Biochem. 1994, 29, 29-37

15. Kristiansen, B. and Sinclair, C. G. Production of citric acid in batch culture. Biotechnol. Bioeng. 1978, 20, 1711-1722

16. Kubicek, C. P. and Rhor, M. Citric acid fermentation. CRC Critical Rev. Biotechnol. 1986, 3, 331-373

17. Dawson, M. W., Maddox, I. S., and Brooks, J. D. Evidence for nitrogen catabolite repression during citric acid production by Aspergillus niger under phosphatelimited growth conditions. Biotechnol. Bioeng. 1989, 33, 1500-1504 
18. Chen, H. C. Response-surface methodology for optimizing citric acid fermentation by Aspergillus foetidus. Proc. Biochem. 1994, 29, 399-405

19. Pintado, J. Produccion de acido citrico a partir de efluentes del procesado de mejillon. Modalidades de cultivo y criterios de optimizacion. Ph.D. thesis, University of Santiago de Compostela, Santiago de Compostela, 1995

20. Akhnazarova, S. and Kafarov, V. Experiment Optimization in Chemistry and Chemical Engineering. MIR Publications, Moscow, 1982

21. Box, G. E. P., Hunter, W. G., and Hunter, J. S. Estadistica para Investigadores. Ed. Reverte, Barcelona, 1989

22. Bernfeld, P. Enzymes of starch degradation and synthesis. Adv. Enzymol. 1951, 12, $379-427$

23. Marier, J. R. and Boulet, M. Direct determination of citric acid in milk with an improved pyridine-acetic method. J. Diary Sci. 1958, 41, 1683-1692

24. Ramesh, M. V. and Lonsane, B. K. Ability of a solid state fermentation technique to significantly minimize catabolic repression of a-amylase production by Bacillus licheniformis M27. Appl. Microbiol. Biotechnol. 1991, 35, 591-593 
Figure 1 Citric acid production (CIT: shadowed bars) and consumed glucose (Gc: light bars) for 11 strains of A. niger. Upper: Solid-state culture on polyurethane foam under the conditions described in text at $96 \mathrm{~h}$. Lower: Submerged culture with the same initial medium at $192 \mathrm{~h}$

Figure 2 Experimental results with strains CBS 554-65, CBS 126-48, CBS 246-65, and CBS 733-88 after a solid-state incubation period of $72 \mathrm{~h}$ in the media defined in Table 1. $\mathrm{N}$ and $\mathrm{P}$ in coded values

Figure 3 Response surface generated from the empirical equation obtained for strain CBS 120-49 in solid-state culture, standardized residuals (in columns), and correlation between observed and expected values $(\mathrm{E})$

Figure 4 Extrapolation of the model obtained for strain CBS 120-49 in solid-state culture following the lineal approximation gradient. Citric acid (CIT): expected values (thick line) and experimental results $(\diamond)$, biomass $(\mathrm{B}, \diamond)$ and consumed glucose $(\mathrm{Gc}, \diamond)$ as a function of the initial concentration of $\mathrm{N}$ (in coded values)

Figure 5 Standardized residuals and correlation between observed and expected values according to the models proposed for strain CBS 554-65 in solid-state culture for the responses: citric acid $\left(\mathrm{CIT}, \mathrm{g}^{-1}\right)$, biomass $\left(\mathrm{B}, \mathrm{g}^{-1}\right)$, and consumed glucose $\left(\mathrm{Gc}, \mathrm{g} \mathrm{l}^{-1}\right)$

Figure 6 Response surfaces obtained from the empirical models corresponding to citric acid (CIT), biomass B, and consumed glucose (Gc) with strain CBS 554-65 in solidstate culture as a function of the initial concentration of $\mathrm{N}$ and $\mathrm{P}$ (in coded values)

Table 1 Experimental domain and codification criteria of the independent variables

\begin{tabular}{llll}
\hline & \multicolumn{2}{l}{ Natural values } \\
\cline { 3 - 4 } Coded values & $\mathrm{N}\left(\mathrm{mg} \mathrm{l}^{-1}\right)$ & $\mathrm{P}\left(\mathrm{mg} \mathrm{l}^{-1}\right)$ \\
\hline-1 & 710 & 60 \\
0 & 955 & 90 \\
1 & 1,200 & 120 \\
\hline Increments & 1 & 245 & 30 \\
\hline
\end{tabular}

Codification: 


$$
\mathrm{V}_{\mathrm{c}}=\left(\mathrm{V}_{\mathrm{n}}+\mathrm{V}_{\mathrm{o}} / \mathrm{dV}_{\mathrm{n}}\right)
$$

Decodification:

$$
\mathrm{V}_{\mathrm{n}}=\mathrm{V}_{\mathrm{o}}+\left(\mathrm{d} \mathrm{V}_{\mathrm{n}} \mathrm{p} \mathrm{V}_{\mathrm{c}}\right)
$$

$\mathrm{V}_{\mathrm{c}}$ : Coded value

$\mathrm{V}_{\mathrm{n}}$ : Natural value

$\mathrm{V}_{\mathrm{o}}$ : Natural value in the center of the domain

$d V_{n}$ : Increment of $V_{n}$ corresponding to one unit of $V_{c}$

Table 2 Results of the experimental plan and analysis of the significance of the

\begin{tabular}{|c|c|c|c|c|c|c|c|}
\hline $\mathrm{N}$ & $\mathrm{P}$ & $\mathrm{Y}$ & $\hat{\mathrm{Y}}$ & & Coefficients & $\mathrm{t}$ & Model \\
\hline 1 & 1 & 14.56 & 14.87 & & 9.45 & 39.73 & 9.45 \\
\hline 1 & -1 & 6.82 & 7.13 & & 1.55 & 4.62 & $1.55 \mathrm{~N}$ \\
\hline-1 & 1 & 8.12 & 8.43 & & 2.20 & 6.55 & $2.20 \mathrm{P}$ \\
\hline \multirow[t]{2}{*}{-1} & -1 & 7.05 & 7.36 & & 1.67 & 4.96 & 1.67 \\
\hline & & & & & & & NP \\
\hline \multirow[t]{3}{*}{0} & 0 & 9.73 & 9.45 & & & Average & \\
\hline & & & & & & response $=$ & \\
\hline & & & & & & 9.45 & \\
\hline \multirow[t]{4}{*}{0} & 0 & 9.91 & 9.45 & & & Average & \\
\hline & & & & & & central & \\
\hline & & & & & & response $=$ & \\
\hline & & & & & & 9.76 & \\
\hline \multirow[t]{2}{*}{0} & 0 & 8.89 & 9.45 & & & $\operatorname{Var}(\mathrm{Ee})=$ & \\
\hline & & & & & & 0.453 & \\
\hline \multirow[t]{3}{*}{0} & 0 & 10.52 & 9.45 & & & $\mathrm{t}(\alpha<0.05 ; \mathrm{v}$ & \\
\hline & & & & & & $=4)=3.182$ & \\
\hline & & SS & $\mathrm{df}$ & QM & & & \\
\hline \multirow[t]{4}{*}{ Model } & & 40.167 & 3 & 13.389 & & QME/QMEe & $\mathrm{F}_{3}^{4}(\mathrm{a}$ \\
\hline & & & & & & $=1.182$ & $=$ \\
\hline & & & & & & & $0.05)$ \\
\hline & & & & & & & $=9.01$ \\
\hline Error & & 2.139 & 4 & 0.535 & & QMLF/QMEe & $\mathrm{F}_{3}^{1}(\mathrm{a}$ \\
\hline
\end{tabular}
proposed model for strain CBS 120-49 in solid-stat culture 


\begin{tabular}{|c|c|c|c|c|}
\hline \multicolumn{2}{|c|}{$\begin{array}{l}\text { Exper. } \\
\text { error }\end{array}$} & 1.358 & 3 & 0.453 \\
\hline \multirow{2}{*}{\multicolumn{2}{|c|}{$\begin{array}{l}\text { Lack } \\
\text { of fit } \\
\text { Total }\end{array}$}} & 0.781 & 1 & 0.781 \\
\hline & & 42.306 & 7 & 6.044 \\
\hline \multicolumn{5}{|c|}{$\begin{array}{l}\text { Y and } \hat{Y} \text { : Observed and expected values o } \\
\text { squares; df: degrees of freedom; QM: qua } \\
\text { error; LF: lack of fit. Variables according }\end{array}$} \\
\hline \multicolumn{5}{|c|}{$\begin{array}{l}\text { Table } 3 \text { Coded and natural values of } \mathrm{N} \text { an } \\
\text { trajectory defined by the linear approxim } \\
\text { of the model obtained for the strain CBS }\end{array}$} \\
\hline \multicolumn{2}{|c|}{ Coded Values } & \multicolumn{3}{|c|}{ Natural Values $\left(\mathrm{mg} \mathrm{l}^{-1}\right)$} \\
\hline $\mathrm{N}$ & $\mathrm{P}$ & $\mathrm{N}$ & & $\mathrm{P}$ \\
\hline 0 & 0 & 955 & & 90 \\
\hline 0.91 & 1.11 & 1,096 & & 123 \\
\hline 1.47 & 1.71 & 1,211 & & 142 \\
\hline 2.19 & 2.47 & 1,360 & & 165 \\
\hline 3.12 & 3.42 & 1,552 & & 195 \\
\hline
\end{tabular}

$$
\begin{array}{ll}
=1.726 & = \\
& 0.05) \\
& =9.55
\end{array}
$$

$\mathrm{r}^{2}=0.949$

error

$$
\begin{array}{lll}
0.781 & 1 & 0.781
\end{array}
$$

adjusted $r^{2}=$

0.912

Total

$42.306 \quad 7$

.044 


\begin{tabular}{llll}
\hline Increments & 1 & 244 & 35 \\
\hline
\end{tabular}

Table 5 Results of the experimental plan and analysis of the significance of the proposed second-order models for the three responses with strain CBS 554-65 in solidstate culture

\begin{tabular}{|c|c|c|c|c|c|c|c|c|c|}
\hline \multirow[b]{2}{*}{$\mathrm{N}$} & \multirow[b]{2}{*}{$\mathrm{P}$} & \multicolumn{3}{|c|}{ Citric acid $\left(\mathrm{g} \mathrm{l}^{-1}\right)$} & \multicolumn{2}{|c|}{ Biomass $\left(\mathrm{g}^{-1}\right)$} & \multicolumn{3}{|c|}{$\begin{array}{l}\text { Consumed glucose }\left(\mathrm{g} \mathrm{l}^{-}\right. \\
\left.{ }^{1}\right)\end{array}$} \\
\hline & & \multicolumn{2}{|l|}{$\mathrm{Y}$} & $\hat{\mathrm{Y}}$ & $\mathrm{Y}$ & $\hat{\mathrm{Y}}$ & \multicolumn{2}{|c|}{$\mathrm{Y}$} & $\hat{\mathrm{Y}}$ \\
\hline 1 & 1 & \multicolumn{2}{|l|}{37.53} & 39.21 & 22.72 & 22.21 & \multicolumn{2}{|c|}{81.09} & 81.35 \\
\hline 1 & -1 & \multicolumn{2}{|c|}{33.15} & 33.57 & 20.41 & 20.48 & \multicolumn{2}{|c|}{92.90} & 91.76 \\
\hline-1 & 1 & \multicolumn{2}{|c|}{126.54} & 27.44 & 16.17 & 16.30 & \multicolumn{2}{|c|}{64.75} & 64.16 \\
\hline-1 & -1 & \multicolumn{2}{|c|}{29.76} & 29.40 & 17.33 & 18.03 & \multicolumn{2}{|c|}{69.21} & 67.22 \\
\hline 1.41 & 0 & \multicolumn{2}{|c|}{37.95} & 36.74 & 20.79 & 21.20 & \multicolumn{2}{|c|}{86.58} & 86.56 \\
\hline-1.41 & 0 & \multicolumn{2}{|c|}{25.57} & 25.46 & 15.79 & 15.29 & \multicolumn{2}{|c|}{55.87} & 57.05 \\
\hline 0 & 1.41 & \multicolumn{2}{|c|}{36.56} & 35.01 & 19.64 & 20.27 & \multicolumn{2}{|c|}{76.67} & 75.68 \\
\hline 0 & -1.41 & \multicolumn{2}{|c|}{32.18} & 32.41 & 20.79 & 20.27 & 84.2 & & 85.21 \\
\hline 0 & 0 & 39.63 & & 39.62 & 20.56 & 20.27 & 80.9 & & 80.45 \\
\hline 0 & 0 & 38.68 & & 39.62 & 19.25 & 20.27 & 78.9 & & 80.45 \\
\hline 0 & 0 & 39.47 & & 39.62 & 20.56 & 20.27 & 79.75 & & 80.45 \\
\hline 0 & 0 & 39.31 & & 39.62 & 20.56 & 20.27 & 81.7 & & 80.45 \\
\hline 0 & 0 & 41.04 & & 39.62 & 20.41 & 20.27 & 81.1 & & 80.45 \\
\hline & Coeff & $\mathrm{t}$ & Model & Coeff & $\mathrm{t}$ & Model & Coeff & $\mathrm{t}$ & Model \\
\hline & 39.62 & 101.69 & 39.62 & 20.27 & 79.125 & 20.27 & 80.45 & 147.67 & 80.45 \\
\hline $\mathrm{N}$ & 3.99 & 12.94 & 3.99 & 2.09 & 10.312 & 2.09 & 10.43 & 24.23 & 10.43 \\
\hline $\mathrm{P}$ & 0.92 & 2.99 & 0.92 & -0.06 & 0.295 & NS & -3.37 & 7.82 & -3.37 \\
\hline NP & 1.90 & 4.36 & 1.90 & 0.87 & 3.025 & 0.87 & -1.84 & 3.02 & -1.84 \\
\hline $\mathrm{N}^{2}$ & -4.26 & 12.91 & -4.26 & -1.01 & 4.664 & -1.01 & -4.32 & 9.36 & -4.32 \\
\hline $\mathrm{P}^{2}$ & -2.96 & 8.95 & -2.96 & -0.05 & 0.231 & NS & 0.29 & $0.62 \mathrm{~S}$ & NS \\
\hline & $\hat{\mathrm{Y}}=$ & & $\hat{\mathrm{Y}}_{\mathrm{o}}=$ & $\hat{\mathrm{Y}}=$ & & $\hat{\mathrm{Y}}_{\mathrm{o}}=$ & $\hat{\mathrm{Y}}=$ & & $\hat{\mathrm{Y}}_{\mathrm{o}}=$ \\
\hline & 35.2 & & 39.6 & 19.6 & & 20.3 & 78.0 & & 80.5 \\
\hline & & Var (Ee & $=0.75$ & & $\operatorname{Var}(\mathrm{Ee}$ & $=0.328$ & & Var (Ee & $=1.484$ \\
\hline & $\mathrm{t}(\alpha<0$. & $05 ; \mathrm{v}=4$ & $=$ & $\mathrm{t}(\alpha<$ & $0.05 ; \mathrm{v}=$ & $4)=$ & $\mathrm{t}(\alpha<0$ & $05 ; \mathrm{v}=4$ & \\
\hline
\end{tabular}




\begin{tabular}{|c|c|c|c|c|c|c|c|c|c|c|}
\hline & \multicolumn{4}{|l|}{2.776} & \multicolumn{3}{|l|}{2.776} & \multicolumn{3}{|l|}{2.776} \\
\hline & SS & $\mathrm{df}$ & & $\mathrm{QM}$ & $\mathrm{SS}$ & df & QM & $\mathrm{SS}$ & df & QM \\
\hline Model & 315.55 & 5 & & 63.110 & 45.16 & 3 & 15.054 & 4 & 1107.67 & 276.92 \\
\hline Error & 10.91 & 7 & & 1.559 & 3.17 & 9 & 0.353 & 8 & 14.95 & 1.87 \\
\hline $\begin{array}{l}\text { Exper. } \\
\text { error }\end{array}$ & 3.04 & 4 & & 0.759 & 1.31 & 4 & 0.328 & 4 & 5.94 & 1.48 \\
\hline \multicolumn{11}{|l|}{ of fit } \\
\hline \multirow[t]{7}{*}{ Total } & 326.46 & 12 & & 27.205 & 48.21 & 12 & 4.018 & 12 & 1124.09 & 93.67 \\
\hline & \multicolumn{4}{|c|}{$\mathrm{QME} / \mathrm{QMEe}=3.458$} & \multicolumn{3}{|c|}{$\mathrm{QME} / \mathrm{QMEe}=1.134$} & \multicolumn{3}{|c|}{$\mathrm{QME} / \mathrm{QMEe}=1.519$} \\
\hline & \multicolumn{4}{|c|}{$\mathrm{F}_{4}^{3}(\alpha=0.5)=6.59$} & \multicolumn{3}{|c|}{$\mathrm{F}_{4}^{5}(\alpha=0.05)=6.26$} & \multicolumn{3}{|c|}{$\mathrm{F}_{4}^{4}(\alpha=0.05)=6.39$} \\
\hline & \multicolumn{4}{|c|}{$\mathrm{QMLF} / \mathrm{QMEe}=2.053$} & \multicolumn{3}{|c|}{$\mathrm{QMLF} / \mathrm{QMEe}=1.075$} & \multicolumn{3}{|c|}{$\mathrm{QMLF} / \mathrm{QMEe}=1.259$} \\
\hline & \multicolumn{4}{|c|}{$\mathrm{F}_{4}^{7}(\alpha=0.05)=6.09$} & \multicolumn{3}{|c|}{$\mathrm{F}_{4}^{9}(\alpha=0.05)=6.00$} & \multicolumn{3}{|c|}{$\mathrm{F}_{4}^{8}(\alpha=0.05)=6.04$} \\
\hline & \multicolumn{4}{|c|}{$\mathrm{r}^{2}=0.967$} & \multicolumn{3}{|c|}{$\mathrm{r}^{2}=0.937$} & \multicolumn{3}{|c|}{$r^{2}=0.985$} \\
\hline & \multicolumn{4}{|c|}{ adjusted $\mathrm{r}^{2}=0.943$} & \multicolumn{3}{|c|}{ adjusted $\mathrm{r}^{2}=0.912$} & \multicolumn{3}{|c|}{ adjusted $r^{2}=0.980$} \\
\hline \multicolumn{11}{|c|}{$\begin{array}{l}\text { Y: Observed values; } \hat{Y} \text { : } \\
\text { squares; df: degrees of } \\
\text { error; LF: lack of fit }\end{array}$} \\
\hline \multicolumn{11}{|c|}{$\begin{array}{l}\text { Table } 6 \text { Comparison between the tendencies of } \mathrm{N} \text { and } \mathrm{P} \text { requirements in the five most } \\
\text { productive strains in solid-state culture and those obtained in suberged culture (Pintado } \\
\text { et al.) }\end{array}$} \\
\hline \multirow[b]{3}{*}{ Strain } & \multicolumn{6}{|c|}{ Submerged culture (192 h, 264 h) } & \multicolumn{4}{|c|}{ Solid-state culture $(72 \mathrm{~h})$} \\
\hline & \multirow[b]{2}{*}{ Tendency } & & \multicolumn{4}{|c|}{ Values at the maximum } & & \multicolumn{3}{|c|}{ Values at the maximum } \\
\hline & & & $\begin{array}{l}\text { CIT } \\
\left(\mathrm{g} \mathrm{l}^{-1}\right)\end{array}$ & $\begin{array}{l}\text { Gc }(g \\
\left.1^{-1}\right)\end{array}$ & $\begin{array}{l}\mathrm{CI}^{\prime} \\
(\%\end{array}$ & $/ \mathrm{Gc}$ & Tendency & $\begin{array}{l}\text { CIT } \\
\left(\mathrm{g} \mathrm{l}^{-1}\right)\end{array}$ & $\begin{array}{l}\text { Gc }(g \\
\left.1^{-1}\right)\end{array}$ & $\begin{array}{l}\text { CIT/Gc } \\
(\%)\end{array}$ \\
\hline \multicolumn{11}{|l|}{ CBS } \\
\hline $\begin{array}{l}554- \\
69^{\mathrm{a}}\end{array}$ & N-1 P-1 & & 35.09 & 107.3 & 32. & & $\mathrm{~N}+1 \mathrm{P}+1$ & 46.56 & 83.18 & 55.98 \\
\hline $\begin{array}{l}120- \\
49^{\mathrm{b}}\end{array}$ & N-1 P-1 & & 4.46 & 99.92 & 4.4 & & $\mathrm{~N}+1 \mathrm{P}+1$ & 14.56 & 89.21 & 16.32 \\
\hline $\begin{array}{l}126- \\
48^{\mathrm{b}}\end{array}$ & N-1 P-1 & & 6.70 & 92.06 & 7.2 & & $\mathrm{~N}+1 \mathrm{P}+1$ & 13.60 & 97.11 & 14.00 \\
\hline
\end{tabular}




\begin{tabular}{lllllllll}
\hline $\begin{array}{l}246- \\
65^{\mathrm{a}}\end{array}$ & $\mathrm{N}+1 \mathrm{P}+1$ & 13.94 & 108.00 & 12.91 & $\mathrm{~N}+1 \mathrm{P}-1$ & 9.26 & 93.99 & 9.85 \\
$733-$ & $\mathrm{N}+1 \mathrm{P}+1$ & 15.09 & 98.00 & 15.40 & $\mathrm{~N} 0 \mathrm{P} 0$ & 12.69 & 91.24 & 13.90 \\
88 & & & & & & & & \\
\hline
\end{tabular}

